\title{
Tropical Dry Forests in the Global Picture: The Challenge of Remote Sensing-Based Change Detection in Tropical Dry Environments
}

\author{
Betsabé de la Barreda-Bautista ${ }^{1}$, Alejandra A. López-Caloca ${ }^{1}$, \\ Stephane Couturier ${ }^{2}$ and José Luis Silván-Cárdenas ${ }^{1}$ \\ ${ }^{1}$ Centro de Investigación en Geografía y Geomática "Ing. Jorge L. Tamayo" \\ ${ }^{2}$ Universidad Nacional Autónoma de México (UNAM). Instituto de Geografía \\ Mexico
}

\section{Introduction}

Global environmental change has recently pushed the scientific community in the quest for more comprehensive spatial information on the continental biosphere. In terms of climate change, ecosystem monitoring has become one of the priorities to better understand the evolution of terrestrial carbon stocks, as well as to foster conservation policies for these carbon stocks. According to IPCC (2002), deforestation and land clearing activities, mostly from sub-tropical regions, contributed with one fifth of the greenhouse gas emission during the 1990s.

The tropical dry forests are one of the most extended tropical forested ecosystems, and yet have received only recent attention from the scientific community. This ecosystem is also scarcely represented in the international protection schemes, which perhaps causes increased vulnerability of this ecosystem to the tropical fingerprint of global human development. Additionally, the climatic conditions are relatively attractive for human settlement and the ecosystem has historically supported dense agriculture activity. In megadiverse Mexico for example, these forests extend up to $60 \%$ of tropical forests, and an estimated $30 \%$ of this extent is considered as highly modified under anthropic pressure. The annual deforestation rate of the deciduous tropical dry forest in Mexico has been evaluated at around $1.4-2 \%$. The contribution of the latter to climate change is manifolds, including carbon emissions, increased albedo and regional hydrographic cycle alteration. Moreover, the very loss of biodiversity derived from the conversion of forest to grassland for pasture is considered as a triggering factor for future forest fires and conversion to more grassland.

The monitoring and analysis of the forest distribution pattern, including phenological and anthropogenic modifications, contributes to the uneasy task of slowing down the tendency of forest loss. Remote sensing has proved a fundamental tool for such monitoring, owing to its contribution to the study and understanding of the global environment through time, and the calibration of models which help building environmental scenarios in the future. 
However, in the case of tropical dry forests, remote-sensing based studies report high levels of error for its detection and mapping. One of the reasons for this is associated with the seasonality of the vegetation: During the wet season, cloud-free satellite imagery is difficult to acquire, while during the dry season when the imagery is more available, the leaf off configuration of the forest causes misclassification with savanna, shrubland or grassland ecosystems. Other sources of uncertainty are related to tropical dry forest definitions and classification methodology. For example, classification schemes at regional scales have mainly been calibrated on other, better studied, ecosystems, and have led to poor accuracy results for tropical dry forests and there is no widely accepted, standard methodology so far for the monitoring of this forest type.

This chapter focuses on the specificity of the tropical dry forest ecosystem and its related challenge for remote-sensing based mapping and monitoring. An emphasis is laid on the exploration of change detection techniques in tropical dry environments. The first section of the chapter relates to the global importance and specificity of the tropical dry forest, in terms of biophysical features, ecological function, and role in climate change. In the second section, remote sensing as a tool to monitor forested ecosystems is reviewed. We discuss the difficulties for monitoring tropical dry forests, among which methodological difficulties of change detection techniques, and the potential of the Multivariate Alteration Detection (MAD) as an efficient technique in this case. In the third section, a comparative study of change detection techniques is presented for Landsat ETM+ imagery on a portion of the tropical dry forest along the western coast of Mexico. Finally, a discussion is proposed on the perspectives learned for dry tropical forest monitoring.

\section{Global importance and specificity of tropical dry forest}

Most tropical ecosystems have been subjected to a diminishment of their extension due to the impact of human being's colonization. Murphy \& Lugo (1986) report that about $40 \%$ of the earth's subtropical landmass is dominated by open or closed forest, and, out of this landmass, $42 \%$ would be tropical dry forest (TDF), 33\% would be moist forest, and only $25 \%$ would be wet and rain forest. Large patches of TDF in the Americas are located in Northeastern Brazil and Southeastern Bolivia, Paraguay, and Northern Argentina (52.4\%). The rest of the existing TDF is found in highly fragmented landscapes in Mexico and Central America (Sánchez-Azofeifa et al., 2009).

Since there is a need to generate scientific knowledge on the tropical dry forest, a series of studies regarding its structure (plant height, density), functioning and composition have already been reported. Several efforts have been made at a local and regional level in Central America and the Caribbean (Murphy \& Lugo, 1995; Griscom \& Ashton, 1995)), Brazilian caatinga (Sampaio, 1995), Africa (Menaut, 1995) and Thailand (Rundel \& Boonpragob, 1995), Costa Rica (Sánchez-Azofeifa et al., 2009), islands in Lago Guri, Venezuela (Feeley et al., 2005) and Mexico (Maas, 1995; Martínez-Yrízar, 1995; Trejo \& Dirzo, 2000). In order to monitor their extent, global distribution maps of TDF were built based on the MODIS Vegetation Continuous Fields (VCF) product; an estimated 1,048,700 km² of tropical dry forest remains distributed throughout the three sub-tropical regions. More than half of the forest area (54.2\%) is located within South America, the remaining area being almost equally divided among North and Central America, Africa and Eurasia, with a relatively small proportion (3.8\%) within Australasia and Southeast Asia (Miles et al., 2006). 
The TDF is one of the most predominant types of tropical vegetation in Mexico (Trejo \& Dirzo, 2000). It is distributed in Mexico along the Pacific Coast where it covers large, practically uninterrupted extensions from the South of Sonora and Southeast Chihuahua all the way down to Chiapas, continuing to Central America. It also exists in patches on the Southern most point of Baja California. It takes up a large portion of Chiapas in the Isthmus of Tehuantepec, also including the Gulf' side in Southern Tamaulipas, Southeastern San Luis Potosí, Northern Veracruz, Yucatán and Campeche (Rzedowsky, 1978). This type of vegetation develops in Mexico in regions of warm sub-humid weather, with an annual average temperature above 20 to $29^{\circ} \mathrm{C}$, an annual rainfall of maximum $1200 \mathrm{~mm}$ and between 0 and $1700 \mathrm{~m}$.a.s.l and its spatial distribution is characterized by a heterogeneous matrix of topographic, aspect, climatic and edaphic conditions (Rzedowsky, 1978; Trejo \& Dirzo, 2000). These types of forests generally present only one arborous stratum, the height of the trees generally oscillates between 5 and $15 \mathrm{~m}$, the treetops are convex or flat and their width sometimes matches or surpasses the height of the trees (Rzedowsky, 1978).

According to Rzedowsky (1978) the impact of human activities on this type of vegetation had been considerably less than in other types of vegetation due to the shallow, rocky floors, stating that they are not good for the development of agriculture even though there were regions of TDF which were exploited for livestock farming, selective woodcutting and affected by forest fires. Still, TDF covered around $14 \%$ of the Mexican territory. However, Janzen (1988) assured that the TDF is the most threatened of the major tropical forest types and that this type of vegetation has declined from an original area of 550,000 $\mathrm{km}^{2}$ and only $0.09 \%$ has been granted a conservation status. Later in the $80^{\prime} \mathrm{s}$ and $90^{\prime} \mathrm{s}$ Flores \& Gerez (1994) reported a reduction of 5.42\% of its surface between 1981 and 1992. Ceballos \& García (1995) stated that there is no consensus about the rates of deforestation in the Neotropics. However, large dry forest patches had disappeared mainly to support agriculture and cattle ranching activities. Trejo \& Dirzo (2000) found that in Mexico 73\% of the TDF has been altered, degraded or converted mainly into agricultural or livestock grasslands.

Quadri de la Torre (2000) states that this ecosystem took up an area of approximately 16 million hectares in the 1950's, of which less of a third remained in that time due to deforestation. One of the last studies made and one of the first to use remote sensing (Miles et al, 2006) demonstrates that in Latin America TDF experienced the greatest decreases between 1980 and 2000 in percentage of forested area, with an estimated figure of $12 \%$, and the main causes for change and loss in these type of ecosystems were mainly due to climatic changes, fires, forest fragmentation, conversion to agriculture and population growth.

\subsection{Ecological functions and ecosystem services}

The relatively simple structure of dry forests makes them more suitable to unravel ecological functions, patterns and processes than their wet counterparts, and, indeed, some of the most significant insights into ecosystem structure and function in the tropics have had their basis in research conducted in dry rather than in wet forests (Bullock et al., 1995).

The distinctive characteristic of TDF is the availability of humidity. It creates a very clear physiognomic contrast between the dry and rainy seasons. The dry season has a length of 7 to 8 months and the vegetation formations lose their leaves (Rzedowsky, 1978). This creates 
a vegetation's hydric and available mineral nutrients deficit, giving as a result a highly complex and diverse ecosystem (Bullock et al., 1995). The seasonality that the TDF presents becomes a dominant ecological force when temporal patterns of biological activity such as growth or reproduction become synchronized with the availability of water or when the geographic distributions of plant or animal taxa are constrained by moisture limitations during certain times of the year (Murphy \& Lugo, 1986).

Ecosystem services refer to the biological properties or processes in forests. They also represent human population benefits derived directly or indirectly from ecosystem functions. Ecosystem services consist of flows of materials, energy, and information from natural capital stocks combined with manufactured and human capital services to produce human welfare (Constanza et al., 1987). For example, forest ecosystems may absorb significant quantities of carbon dioxide. As a result of this, in the last decades a considerable amount of interest has appeared to increase the amount of carbon content in the land vegetation by means of forest preservation, reforestation, agroforestry and other methods of land use.

Tropical dry forests are less diverse than wet forests; total biomass of trees and net annual primary productivity (NPP) are also lower, but the diversity of plant life forms is greater. Improved measurements of NPP have included annual litterfall and have suggested high values of forest biomass (Martínez-Yrízar et al., 1996; Bullock et al., 1995). TDF presents well defined phenological cycles, which make them potential proxies for the biological response to climate change and specifically to drought effects. According to Maass et al. (2005) little research has been conducted therefore, little is known about the ecosystem services provided by the TDF.

Kalacska et al. (2008) point out the need of characterizing, as accurately as possible, the initial state and extent of the forest to estimate the payments for environmental services. On his own, it studies one of the most important ecosystem services of the TDF: Carbon sequestration.

Maass et al. (2005) provide a conceptual framework to construct an integrated understanding of ecosystem services delivered by tropical dry forest of the Pacific Coast of Western Mexico. In order to explain this, the structural and functional aspects of the natural and transformed ecosystems were considered, as well as a more recent understanding regarding social dimensions of ecosystem management. Maass et al. (2005) identified nine main services in the Chamela Region, Jalisco, Mexico, which are fresh water, agricultural and pastoral goods, diverse resource provisioning, biodiversity, climate regulation, soil fertility maintenance, flood control, bio-regulation and scenic beauty. Additionally, Pielke et al. (2002) also claim that the climate-related ecosystem services that tropical forests provide include the maintenance of elevated soil moisture and surface air humidity, reduced sunlight penetration, weaker near-surface winds and the inhibition of anaerobic soil conditions.

\subsection{Tropical dry forest removal in the context of global warming}

The human activity is causing deforestation at global scale. The main driver of deforestation is land use change, including conversion to grasslands and to agricultural land, forest fires and irrational woodcutting, among others. The conversion through shifting cultivation and clearing of secondary vegetation makes significant contributions to global emissions of greenhouse gases today, and has the potential for large additional emissions in future 
decades. Additionally, the non-sustainable exploitation of timber where extraction exceeds regeneration and reforestation implies a surplus of emissions of greenhouse gases (Intersecretarial Commission of Climatic Change 2009).

The consequences of deforestation are multifold: Firstly the production of considerable carbon emissions due to the combustion and decomposition of vegetable biomass and also to the loss of organic carbon located in the soil.

Deforestation also impacts on regional and global climates, not only because of emissions of the greenhouse gases, but also because of the increased albedo and evapotranspiration derived (IPCC, climate change and biodiversity, 2009). The regional consequences of the future climate change are not yet known, but it is highly probable that the changes in variables induced by climate change may modify in turn the regional climates and may induce unexpected effects over the weather conditions in different regions. Local and regional climate changes may consist of alterations in the length of the agricultural seasons, in the availability of water or in a greater incidence of perturbation regimes (extreme values of high temperatures, flooding, droughts, forest fires or plagues), which will, in turn, notably impact the structure and function of the natural and artificial environments (IPCC, 1997).

Strictly in terms of $\mathrm{CO}_{2}$ emissions in the world which seem to prevail in the factors of global warming (Mintzer, 1992, as cited in Ordoñez, 1999), deforestation contributes roughly one fourth of the emissions while fossil fuel consumption by humans contributes roughly three fourths (IPCC, 2009). However, deforestation has consequences beyond global warming, much further into the multi-threatening global change: for example, the fragmentation of habitats and conversion of extensive land uses to intensive ones cause a severe loss in biodiversity. In fact, changes in ecosystems may have important consequences within global warming. For example, the alteration of tropical landscapes, primarily the conversion of forests to agriculture or pasture, changes the partitioning of insolation into sensible and latent turbulent heat forms. Less transpiration associated with the agricultural and pasture regions results in less thunderstorm activity over this landscape (Pielke et al., 2002). Each change in the quantity or quality of types of natural capital and ecosystem services may impact human welfare. These are part of both small changes at large scales and large changes at small scales; in other words changes in particular forms of natural capital and ecosystem services which both alter the costs or benefits of maintaining human welfare (Constanza et al., 1987).

From the strict global warming perspective, tropical ecosystems in general, and forests in particular, can accumulate a significant amount of the global carbon in biomass (Pfaff, 2000). As a consequence, there is a great need to estimate, map and monitor with greater precision the accumulated carbon in the forests (Goetz, 2009). The amount of biomass is generally much greater in tropical rainforests than in tropical dry forests. However, worldwide many tropical rainforests are replaced by TDF (William, 1985), especially in South America and Africa. Rainforests are converted to Savanna and other dry tropical forest types, often irreversibly, because of fire events. This phenomenon justifies the importance of studying TDF carbon stocks in spite of their lesser content with respect to rainforests.

In Mexico, TDF, described as a low size tropical deciduous forest, has been one of the ecosystems most affected by land use change. It is also likely that in the future, an increasing land use change trend will continue due to the increasing demand over ecosystem services and natural resources. Burgos and Maass (2004) unveil the causes and consequences of 
tropical dry forest conversion into other types of land use in Mexico. They show how much of the TDF has already been converted to pasture and agricultural land. Human settlements surrounding the reserve of Chamela (Jalisco, Mexico) are organized under the Ejido land tenure system where peasants have tended to clear TDF for slash and burn cropping and pasture for cattle grazing. Ejidos are considered land use administrative units under the control of local peasant communities. Decisions on land use change at the Ejido level are mostly driven by the needs to fill local market expectations. The decisions are nevertheless controlled and/or motivated by Mexican agrarian and environmental regulations (SánchezAzofeifa, 2009).

Ordoñez \& Masera (2001) report that one of the main emitters of greenhouse gases in Mexico is land use change: 30.2 million tons of carbon released each year; the total emissions produced in Mexico represent $1.4 \%$ of the total carbon emissions around the globe. The greenhouse gas which contributes the most to global warming is $\mathrm{CO}_{2}$ and tropical forests are said to play a very important role in the cycle of this gas. They claim deforestation produced $69.5 \%$ of the reported $\mathrm{CO}_{2}$ emissions in Mexico in 2006.

In order to quantify the TDF ecosystem's biomass, carbon $(\mathrm{C})$ and nitrogen $(\mathrm{N})$ pools of both intact forests and converted sites, Jaramillo et al (2003) sampled the total aboveground biomass (TAGB), and the $\mathrm{N}$ and $\mathrm{C}$ pools of two floodplain forests, three upland dry forests, and four graze lands that had been dry forest extents. The lack of a consistent decrease in soil pools caused by land-use change suggests that $\mathrm{C}$ and $\mathrm{N}$ losses result from the burning of aboveground biomass. It is estimated that in México dry forest landscapes store approximately $2.3 \mathrm{Pg} \mathrm{C}$, which is about the same C stored by the evergreen forests in that country (approximately $2.4 \mathrm{Pg} \mathrm{C}$ ). Potential $\mathrm{C}$ emissions to the atmosphere from the burning of biomass in the dry tropical landscapes of Mexico may be higher (708 $\mathrm{Tg} \mathrm{C})$, as compared with from evergreen forests $(569 \mathrm{Tg} \mathrm{C}$ ). Efforts to determine the status of TDFs in Mexico are particularly critical in certain regions with the highest diversity and endemism of TDF in the world. These regions include the Yucatan Peninsula, the coast of the State of Jalisco, the Balsas and Santiago river basins and scattered areas along the Gulf coast (Trejo \& Dirzo, 2000, 2002).

\section{Remote sensing as a tool to monitor forested ecosystem}

Given the need to create a strategy to go deeper into the behavior of TDF, it is necessary to go further into characterization through the dominion of a spatial and temporal scale. In this work, the resources of geospatial information such as satellite images are used. The identification of places is essential in the determination of spatial patterns. The related images are connected to the geographical characteristics of the place. Nowadays, satellite images are tools which help us to identify geographic features or places that are associated to a certain type of application; provide a context of the place as well as helping us identify natural and environmental aspects of the geographical space. However, there are different ways to approach the geospatial problem in a more integral way, such as using more technological, geospatial tools that allow organizing and optimizing the use in the handling of the information. This is presented within a conceptual framework in Geomatics where the interaction of the changes in landscape is motivated with the appropriate models in order to simulate identified social, economic and ecological processes, and their dynamics and interactions given by the social actors as well as the government itself, from a territorial point of view (Reyes et al., 2006). 
The identification, follow-up and notification of the changes experienced by the terrestrial cover may be made through field information, geographic statistics, models based on forest inventories, remote sensing techniques, flow measurements, soil sampling and ecological studies (IPCC, 2002). In Mexico, as in the world, the ecosystems are in permanent change due to natural causes and the pressure exercised upon them by human beings. Remote sensing and geographic information systems have been fundamental tools in monitoring these changes throughout the years.

These sciences allow the pinpointing and following-up of these changes from a historical perspective due to their temporal resolution. Remote sensing has been a very valuable instrument in the observation and follow-up of Earth and one of its most relevant contributions is the study of the weather and the following-up of the processes happening on it (Chuvieco, 2002). However, there are several challenges associated with developing the remote sensing inputs needed to understand landscape dynamics. Land use and land cover change studies are often based on information about landscape structure and composition at different spatial and temporal resolutions derived from remotely sensed data.

There are two change detection approaches according to Chuvieco (2002) considering a temporal aspect: a multiseasonal and a multiannual approach. The first one refers to following patterns by seasons in the same year where, for example, the changes in the phenology of the vegetation can be analyzed. The multiannual approach refers to the detection of changes happening between two or more dates. This last approach is the one this work is focussed on in order to monitor the changes in soil cover and its implication in climatic change.

The changes in the terrestrial cover and the changes in land use have important implications for the future climatic changes on Earth. This is why the need to understand the interactions between human activity and natural resources appears. These same interactions are seen reflected in the change patterns of land use/terrestrial cover. These changes are a process widely distributed, accelerated and significant, mainly caused by human actions and, in many cases, also bring about changes which impact on humanity (Rosete et al., 2008). This is why remote sensing proves to be fundamental in the evaluation of changes in the patterns of deforestation and changes in land use, because this allows a qualitative and quantitative analysis of the changes happening in the ecosystems.

Remote sensing has been used for the extraction of information from the environment. Within the most common applications we find coverage mapping, changes in land use, weather monitoring, biomass accounting, vegetation phenology, desertification, deforestation, monitoring of forest fires and natural disaster prevention, all of which are closely linked to climatic change.

There are several sensors which have made possible all the studies above mentioned. However, it is noteworthy to mention that the Landsat program has a compilation of images dating 40 years, which represents the lengthiest registry of information of the Earth's surface obtained in a global and repetitive way from space (USGS, 2010). The availability of periodic data obtained through satellite observation has made possible for climatic change detection to be one of the most important applications in remote sensing. Since 2009, the information obtained from this program has become available providing a lot of material to make scientific studies, as well as the advance and implementation of new methodologies to study Earth's surface from different fields. 


\subsection{Importance of change detection for ecosystem monitoring}

Mapping TDF distribution remains a difficult challenge in spite of the diversity and potential of the remote sensing data that have been employed for this task so far. Parts of the challenge are because most of the studies have been performed in tropical evergreen forest, these studies are successful in the characterization of this forest and they obtained good results in accuracy (e.g. user's accuracy of MODIS derived global map for broadleaf evergreen forests: MODIS team, 2003). TDF has received considerably less attention and the extraction of TDF information from remote sensing imagery has been hampered by at least three factors:

1. The difference in the classification method for TDF cover extraction.

2. The difference in definitions of TDF among countries and scientists.

3. The difficulty in mapping or characterizing TDF with remote sensing data.

Regarding points 1 and 2, the extraction of the distribution of ecosystems is in general a complex task because vegetation classification systems differ (e.g. bioclimatic types, global biogeographic classifications, vegetation types according to the Marrakech's accords, etc.) along with natural boundaries of these ecosystems (Miles et al., 2006; Kalacska et al., 2008). Another interesting difference reported by Lucas et al. (2004) is related to natural boundaries of tropical ecosystems, due to excessive loss and fragmentation.

With regard to point 3 , the noise in the remote sensing data due to atmospheric conditions causes more problems than for evergreen forests (Lucas et al. 2004), because of the seasonal phenology of the forest. During wet season, the acquisition of the imagery is hampered by cloud cover. During dry season, when more imagery are available, a varying percentage of trees is leafless which causes the forest to be possibly misinterpreted, because of a similar spectral signature, with non treed ecosystems or with highly modified evergreen forests.

Couturier (2010) assessed the accuracy of the MODIS derived global map MOD12Q1 for the major forest biomes in the total extent of mega-diverse Mexico. He found that the greatest amount of error occurred for the broadleaf deciduous forests while evergreen forests were relatively well mapped; oak forests tended to be confused with grassland and TDF tended to be confused with evergreen forests. Only 39\% of the TDF in Mexico were correctly mapped. His findings corroborated Kalacska et al. (2007), who found only 36\% accuracy for the TDF class in Mexico's Chamela Natural reserve and Costa Rica. The TDF was significantly underrepresented in the land cover maps. In the case of confusion with evergreen forests, this means that carbon stock estimations derived from the maps are optimistically flawed by a significant amount.

In the perspective of precise ecosystem service tracking and global warming mitigation models, there seems to be a need for enhancing classification methods or/and optimizing remote sensing inputs for the estimation of TDF extent.

\subsection{Difficulties for monitoring dry forest}

In order to estimate the total value of ecosystem services, it is necessary to estimate the total global extent of the ecosystem (Constanza et al., 1987) and the rate of changes of the ecosystem extent (Kalacska et al., 2008). In the last few years efforts have been focused in the creation of models that help to create future scenarios which can help in the management of issues related to the preservation of the biodiversity and sustainable management of natural resources (Lambin, 1997). 
The changes in vegetation cover and land use are dynamic processes. Therefore, the transitions are produced in different ways and in different places within its own limitations, as a response to social, economic or environmental factors. Change analyses provides fundamental information for the managing and planning of territory, the comparison in landscaping dynamics, in environmental impact studies (Serra et al., 2001), the detection of modifications in the conditions, abundance and distribution of species and the updating and systematization of natural resources inventories, among others.

This information, in order to determine significant changes in those critical components in an ecosystem, is one of the initial conditions and it will assist as a basis for the development of managing and preservation plans for ecosystems and the preservation throughout time of the natural resources sustaining these ecosystems (Ramírez-Bojórquez et al., 2006). Balance between the natural habitat and human landscape could determine the future of the conservation of biological diversity in large areas of the planet. For this reason, it is important to monitor these conversions in the habitats. (Lee et al., 1995 as cited in López et al., 2001).

Transformation in ecosystems should be handled taking into account three main questions: Which environmental and cultural variables are mainly contributing to the changes on Earth's cover? Which are the places affected by these type of changes? How is the progress of these changes? The challenge, in order to model and monitor the terrestrial cover, is answering these questions in such a way that these studies become crucial for any decisionmaking (Lambin, 1997).

Because of all the above mentioned, the importance of monitoring natural environments and the research and improvement of change detection methods are an issue under constant development in order to insert itself in the decision-making processes and investigation lines which interest the scientific community and society as well as is the case of climatic change.

It is important to note that a better change detection is based on the better understanding of the process and driving force of change (Sui et al., 2008). This is why it is interesting to know the behavior of the TDF because proposing efforts towards the conservation of the tropical dry forest would help alleviate, among other things, the emission of greenhouse gases. This is important because it has been demonstrated that changes in these kinds of ecosystems have caused changes in the carbon deposits (Estrada-Salvador \& Navar, 2009).

In order to analyze and understand the ecosystem services like the capture of carbon that is in the TDF, it is necessary to know the intrinsic characteristics of the forests such as temperature, rainfall, soil characteristics and - of course and most importantly for the information within this chapter - the changes in land cover as well as the change in land use. With this, the number of biomes is calculated as well as the changes they have suffered throughout time in order to make estimations in these ecosystem services. The most significant impact of human activities on $\mathrm{C}$ storage comes through deforestation (Houghton et al., 1999, as cited in Pfaff et al., 2000). It is necessary for this to know the baselines for land use and translate observable land use and physical characteristics of sites into measures of carbon (Pfaff et al., 2000).

Land-cover change provides an additional major forcing of climate, through changes in the physical properties of the land surface (Pielke et al., 2002).

To estimate the change in cover and to understand the forces and factors related to these changes can be important measures to decrease these practices and in this way minimize the carbon emissions which would help to alleviate climatic change, biodiversity and endemic 
species conservation, keep land in natural conditions, regulate the water cycle with direct benefits in a better microclimate and a better recharge of aquifers, among others (EstradaSalvador \& Navar, 2009).There are many ways to tackle a change detection study and they should work mainly towards the proposed study's objectives, without leaving aside technical matters such as the equipment's availability, images and processing software. This line of investigation through remote sensing has become essential for several applications. Table 1 (below) shows the relationship between the most explored applications in change detection and the methods being used for each one of them.

\begin{tabular}{|l|l|}
\hline \multicolumn{1}{|c|}{ Typical applications } & \multicolumn{1}{c|}{ Used Methods } \\
\hline $\begin{array}{l}\text { Change in land use or } \\
\text { landscape cover }\end{array}$ & $\begin{array}{l}\text { Post-classification comparison, indirect classification of } \\
\text { multi-temporal images, visual interpretation }\end{array}$ \\
\hline Change in vegetation & $\begin{array}{l}\text { Image differencing, images rationing, post-classification } \\
\text { comparison }\end{array}$ \\
\hline Monitoring of natural disasters & $\begin{array}{l}\text { Image differencing, images rationing, regression, fire } \\
\text { models, visual interpretation }\end{array}$ \\
\hline $\begin{array}{l}\text { Changes in urban zones and } \\
\text { SIG updates }\end{array}$ & $\begin{array}{l}\text { Image differencing, images rationing, object-oriented } \\
\text { methods, visual interpretation }\end{array}$ \\
\hline $\begin{array}{l}\text { Object follow-up and } \\
\text { monitoring }\end{array}$ & $\begin{array}{l}\text { Image differencing, images rationing, post-classification } \\
\text { comparison, object-oriented methods, visual } \\
\text { interpretation }\end{array}$ \\
\hline $\begin{array}{l}\text { Research and monitoring for } \\
\text { military applications }\end{array}$ & $\begin{array}{l}\text { Image differencing, images rationing, object-oriented } \\
\text { methods, visual interpretation, time series analysis }\end{array}$ \\
\hline $\begin{array}{l}\text { Other applications (e.g. changes } \\
\text { in wetlands and landscape, } \\
\text { crop monitoring, etc.) }\end{array}$ & $\begin{array}{l}\text { Image differencing, images rationing, post-classification } \\
\text { comparison, object-oriented methods, visual } \\
\text { interpretation }\end{array}$ \\
\hline
\end{tabular}

Table 1. Typical applications in change detection studies and used methods.

\section{Potential monitoring techniques}

In order to analyze the dynamic characteristics of the land covers, a great quantity of techniques has been developed for the extraction of information to allow visualization and understanding of the terrestrial cover through time. Change detection methods have been developed over the last decades and have been improved through time. The techniques being used to make change detection studies are focused on showing the transformations or modifications that have happened in a determined area as a consequence of natural phenomena or man-made actions.

Digital change detection analysis is affected by spatial, spectral and temporal factors (Coppin et al., 2004). The type of method used may give different final results; therefore choosing an effective technique becomes crucial depending on the study's objectives, the case to be studied, the phenological characteristics of the area, etc. The limitations, advantages and disadvantages of each technique must be important points to consider in the analysis, so that the right choice is made with the one that covers the necessary characteristics to get a good result in the change analysis.

Several existing methodologies have been proposed for change detection analyses, which have been modified with the making of different works. They are not exclusive 
methodologies, meaning that some of them use concepts from others and in this way they have evolved in the improvement and development of them. Whichever combination of change detection algorithms and classification routine is applied, it is evident that several alternatives exist and all of them have different degrees of flexibility and availability (Coppin et al., 2004).

New methods and techniques are in constant development and invention (Lu et al., 2004), and it is sought that they are widely used in fields such as the detection, follow-up and modeling of the changes in land use and land cover, forests, ecosystems, natural disasters and urban areas (Sui et al., 2008).

The techniques for the change detection analysis, through digital analysis, have been divided or categorized and described by different authors (Chuvieco, 1998; Coppin et al., 2004; Pacifici, 2007; Niemeyer et al., 2008; Lu et al., 2004) according to the involved processes and the algorithms' characteristics. Each method has a different degree of robustness, flexibility and significance. However, since the change detection techniques require making a complete and complex analysis of multi-temporal, multispectral images with several spatial resolutions and geographic data, nowadays no classification is enough to frame all the algorithms' bases or the developing methods.

Singh (1989) classified the methods in two categories: post-classification change detection and direct comparison with multi-temporal data. Lu et al. (2003) grouped the methods into seven categories: algebra, transformation, classification, advanced models, geographical information system approaches, visual analysis and other approaches. Wyatt (2000) basically groups them in two: post-classification methods and algorithms for quantifying change. Coppin et al. (2004) classified the methods in two large groups: bi-temporal change detection and temporal trajectory analysis. Sui et al. (2008), in turn, classified the methods in seven categories: direct comparison, classification methods, object-oriented methods, time series analysis, visual methods and the hybrid method. These seven categories are classified within the Coppin et al. (2004) classification.

The direct comparison methods use algebraic operations, trying to compare arithmetically bands derived from two different dates (Chuvieco, 1998). These methodologies include image differencing and image rationing, correlation coefficient methods, biophysical variables used to compare values from two images from different years; Coppin et al. (2004) calls this univariate image differencing. The most widely used biophysical variables for this type of analysis are the vegetation indexes, e.g. Normalized Difference Vegetation Index (NDVI), Principal components analysis (PCA), etc. (Coppin et al., 2004).

The research in change detection techniques is still very active as new techniques should be developed to effectively use both the available data obtained through remote sensing, which is increasingly diverse and complex, and expected data from airborne and space-borne sensors under development.

Even a glimpse of the remote sensing literature provides enough evidence to conclude that the images obtained through satellites at different dates may be used to detect and monitor changes happening in the ecosystems (Coppin et al., 2004). However, the efforts towards developing a better understanding of the change detection process should not decrease so that a better understanding of the applications and methodologies on this matter continue to be made.

It is also important to mention that the change detection techniques may focus on three fundamental aspects: "if it changed", which means whether there has been a change in the images or not; "what is changed", which determines which characteristics are changing, 
meaning that it identifies the "from-to" change; and lastly "how it changed", which identifies the change process and trajectories (Sui et al., 2008).

\subsection{Post-classification}

One of the most frequently used methodologies is the post-classification change detection method which involves two steps: In the first step, images acquired at two times comprising the time period of interest are classified independently. In the second step, a pixel-by-pixel or segment-by-segment comparison is carried out in order to determine the type of changes in land cover class. This method has the advantage of minimizing impacts of atmospheric, sensor and environmental differences between multi-temporal images; it provides complete matrix of change information, whereas its disadvantages are the need of a great amount of time and expertise to create accurate classification products (Lu et al., 2004). By adequately coding the classification results, a complete change matrix is obtained, and change classes can be defined by the analyst (Coppin et al., 2004). This method has been applied in studies on land cover change, forest or vegetation change, and urban change (Sui et al., 2008). It is important to mention that the accuracy of this method depends on the accuracy of the classification. The final accuracy resembles very closely to that resulting from the multiplication of the accuracies of each individual classification and may be considered intrinsically low (Coppin et al., 2004).

In order to make image classification, the spectral information is used by a pattern recognition technique. This means that the objects' spectral response is analyzed and separated into classes. The objective of this process is to assign a class to all the image pixels (e.g. bodies of water, types of vegetation, bare soil, and so forth). This way a thematic map is obtained, which means that we get an image with a mosaic of pixels, each one belonging to a particular class. (Ortiz, 2005).

One of the advantages of this method is that the classification of multitemporal images avoids the need to normalize for atmospheric conditions and sensor differences, between the acquisitions. However, the biggest disadvantage is that the performances of the postclassification comparison technique critically depend on the accuracies of the classification maps (Jensen, 1996). In particular, the final change detection map exhibits an accuracy close to the product of the accuracies yielded at the two times. This is due to the fact that postclassification comparison does not take into account the dependence existing between two images of the same area acquired at two different times (Pacifici, 2007). The effectiveness of this alternative depends on how the change classes are spectrally differentiated from the no change classes.

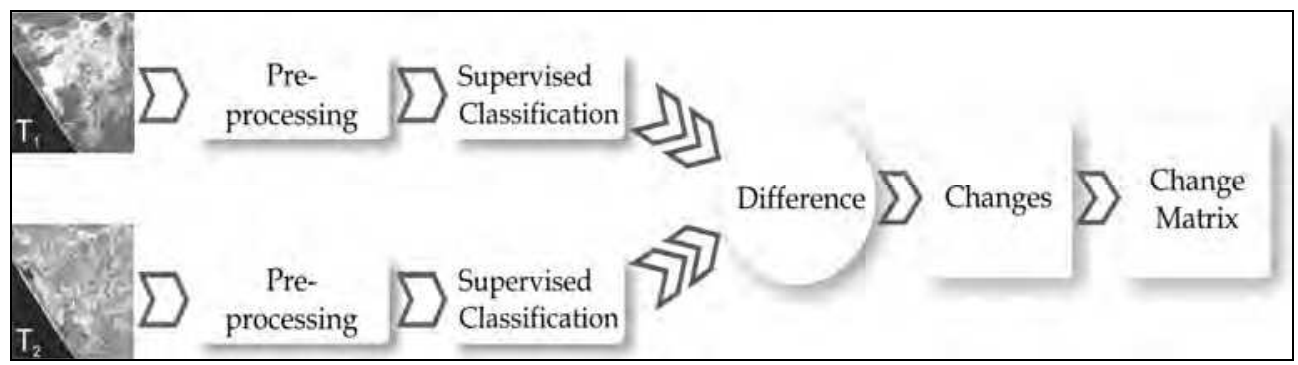

Fig. 1. Scheme of post-classification techniques. 


\subsection{Multivariate Alteration Detection}

The Multivariate Alteration Detection (MAD) (Nielsen and Conradsen, 1997) procedure is based on a classic statistical transformation, referred to as canonical correlation analysis, to enhance the change information in the different images. The property of the Multivariate Alteration Detection transformation is the linear scale invariance. Therefore, with the use of $\mathrm{MAD}$, the preprocessing by linear radiometric normalization becomes unnecessary, meaning that this implies insensitivity to linear differences in atmospheric conditions or sensor calibration at the two different image times.

Canonical correlation analysis investigates the relationship between two groups of several variables. It finds two sets of linear combinations of the original variables, one for each group. Canonical correlation analysis (CCA) is used to measure the strength of association between two sets of variables. The first two linear combinations are the ones with the largest correlation. This correlation is called the first canonical correlation and the two linear combinations are called the first canonical variates. The second two linear combinations are the ones with the largest correlation subject with the condition that they are orthogonal to the first canonical variates. This correlation is called the second canonical correlation and the two linear combinations are called the second canonical variates. Higher order canonical correlations and canonical variates are defined similarly. Nielsen (1998), looks for canonical variates that are as similar as possible as measured by correlation, so he requests positive canonical correlations.

The essence of this method is to transform two groups of multispectral data (two images in time 1 and time 2 in such a way that they show the maximum change (variance) in all the bands in a new set of images (MAD components), so that the change may be seen at the same time in various resulting MADs showing the changes of the different characteristics of the image (Fig. 2).

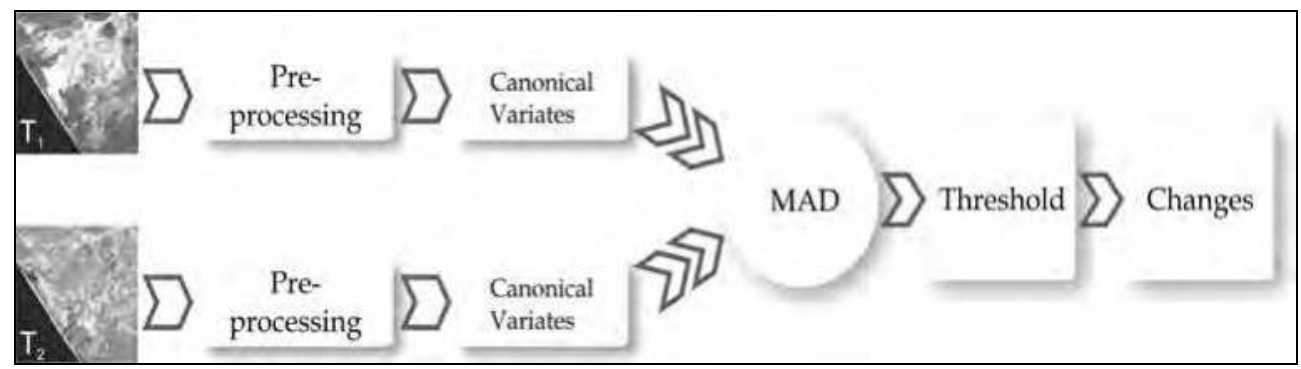

Fig. 2. Scheme of Multivariate Alteration Detection technique.

The mathematical expression of the MAD transformation is:

$$
Z=a^{T} X-b^{T} Y
$$

where $X$ and $Y$ are the two multivariates of two images, $a$ and $b$ are coefficient vectors of linear combinations, and $\mathrm{Z}$ is the difference variable. Variance of $\mathrm{Z}$ is to be the maximized subject to constrain that both $a^{T} X$ and $b^{T} Y$ have unit variances. (Zhang, 2007)

Vectors $\mathrm{a}$ and $\mathrm{b}$ could be solved by employing the established Canonical Correlation Analysis in multivariate statistics (Thompson, 1984). The correlation between $a^{T} X$ y $b^{T} Y$ is 
called canonical correlation. The lower canonical correlation is the larger variance of $\mathrm{Z}$. Therefore, the core idea of MAD is to find out maximum differences between two images by removing correlations between them as much as possible.

$$
\begin{aligned}
& a^{T} X=a_{1} X_{1}+\ldots+a_{p} X_{p} \\
& b^{T} Y=b_{1} Y_{1}+\ldots+b_{q} Y_{q}
\end{aligned}
$$

To find $a$ and $b$ is to define a set of $a$ and $b$ simultaneously, to let us maximize the variance with $\operatorname{Var}\left\{a^{T} X-b^{T} X\right\}$. A multiplication of $a$ and $b$ with a constant $c$ will multiply the variance with $c^{2}$. Therefore a choice concerning a and b must be made and natural choices in this case are requesting unit variance of $a^{T} X$ and $b^{T} Y$. The criterion then is: maximize $\operatorname{Var}\left\{a^{T} X-b^{T} X\right\}$ with $\operatorname{Var}\left\{a^{T} X\right\}=\operatorname{Var}\left\{b^{T} X\right\}=1$. By choosing this, we have

$$
\begin{gathered}
\operatorname{Var}\left\{a^{T} X-b^{T} X\right\}=\operatorname{Var}\left\{a^{T} X\right\}+\operatorname{Var}\left\{b^{T} X\right\}-2 \operatorname{Cov}\left\{a^{T} X, b^{T} X\right\} \\
\operatorname{Var}\left\{a^{T} X-b^{T} X\right\}=-2\left(1-\operatorname{Cov}\left\{a^{T} X, b^{T} X\right\}\right)
\end{gathered}
$$

Also, to find $a$ and $b$ a principal component (PC) analysis can be used. Doing PC transformation generates linear combinations of multiespectral pixel intensities which have maximum variance. The difference between MAD and PC is that PC does not intend to retain the common information between dates, but actually the one that changes. The first PC gathers the stability dimension of the image (stable brightness). The secondary components offer the change which is what interests us (Chuvieco, 2002). The second corresponds to the change between dates with clarity, since the coefficients that are negative represent the change in brightness. The third shows the contrast between the IRC and the other bands and it can be defined as stable greenery. The fourth, according to Chuvieco (2002) may refer to the transition from dry vegetation to a vigorous one.

Theoretically, among all MAD components, the first one with largest variance ought to contain most of the change information, while others contain change information in decreasing order. In practice, in order to understand the physical content of the MAD components, it is possible do correlations between the change areas of the MADs and the original bands (wavelength regions) (Nori et al., 2008). However in this study a supervised classification of MAD components was done in order to understand better those components.

However, this is not the case in practice by visual inspection due to noise in remotely sensed images. Noise may often be modeled as random variables uncorrelated with signals. During MAD transformation, this noise will be concentrated in those MAD components with low canonical correlations, which will result in a deviation of change information distribution from theoretical model, so as to hinder subsequent interpretations of change detection results (Zhang et al., 2007). To solve such a problem, Canty (2010) introduced another orthogonal multivariate linear transformation, called Minimum Noise Fraction (MNF), into change detection as a post-processing step for MAD transformation (Canty, 2010). The objective of MNF transformation is to separate signal from noise as much as possible.

An important problem in satellite images change detection is the one produced by the variations introduced by the observation conditions, atmospheric conditions or the sensor's 
calibration. These effects modify the spectral signatures of land cover classes; therefore it is necessary to homogenize the images through conversion models to physical parameters incorporating the parameters of atmospheric correction and lighting. The MAD components are robust in this aspect, which means they are invariant under any linear transformation including any linear atmospheric corrections that may be made to the data. Therefore such corrections are not necessary (Nielsen, 1998; Canty et al., 2004). Other advantages of this algorithm are that it doesn't require parameters to adjust, it can be applied at an object level, and it can be iterated on no change probability (Canty \& Nielsen, 2008).

\subsubsection{MAD \& thresholding}

The MADs are separated into change and no change classes (the change and no-change), and change thresholds are established. There are different methods to implement the change thresholds. The main idea in the choice of thresholds is to detezct significant changes thrown by the results in the change detection. In order to exploit the change information yielded by the MAD components, statistic criteria have been frequently used, assuming a normal distribution of the MAD components, based on the average standard deviation (Figure 3).

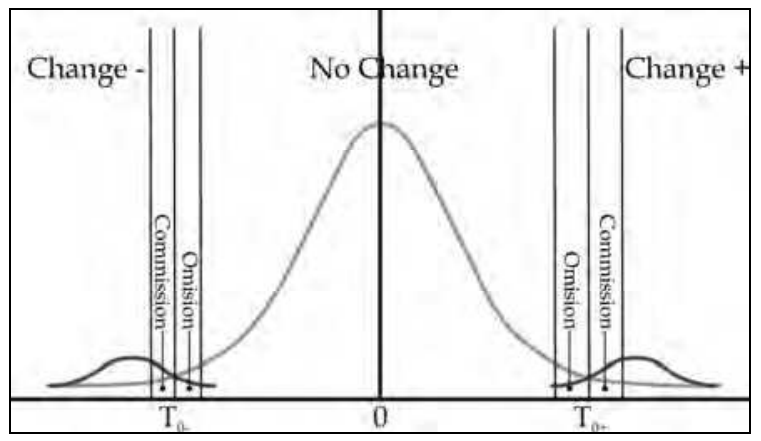

Fig. 3. Definition of Threshold (T). The curve shows MAD components distribution. The centre of the curve represents the "stable areas" or "areas of no change", whilst the areas from the sides represent the "dynamic areas" or "areas of changes detected". The omission and commission areas of the curve represent "over or under estimations" of possible changes detected.

There are several authors who suggest improvements to the threshold by applying unsupervised classification (Canty et al., 2006), or applying different algorithms such as the expectation-maximization algorithm (EM) (Bruzzone \& Fernandez-Prieto 2000). One method is to determine a threshold based on standard deviations $(\sigma)$. The value of the thresholds is placed separately for each MAD component, considering that the intensity values are at $\pm 2 \sigma$ of zero, which corresponds to the unchanged pixels.

\subsection{Comparative study of change detection techniques}

To develop models that allow observing the change dynamics is necessary to understand the causes and consequences of processes linked to global warming. In this study, two different change detection techniques were applied in order to assess land cover changes in 
the Jalisco Coast (Pacific Ocean). First, we focused on change detection based on postclassification comparison. Second, we investigated the usefulness of Multivariate Alteration Detection technique.

The Jalisco Coast, Mexico, has a surface of 1,451,465.85 hectares, corresponding to $17.5 \%$ of the State of Jalisco surface (Fig. 4). Up to 18 types of vegetation can be found in the area, being the most important and representative the tropical dry forest (Castillo et al., 2007).

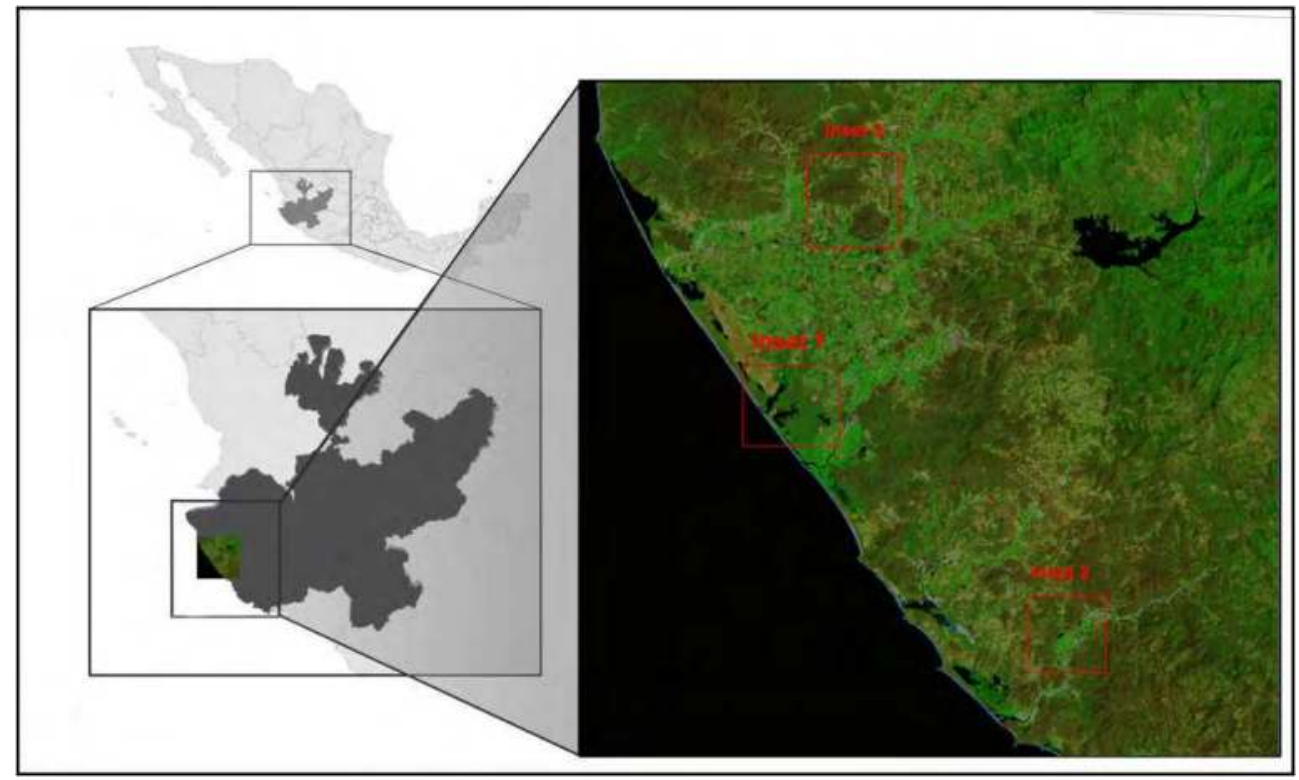

Fig. 4. Research area.

For a complete land cover change detection analysis, four basic remote sensing processes were used. First, a phase is allocated for satellite definition (for its orbital perception and repetition time) and for the sensor (for the desired properties in the image). Afterwards, the pre-processing takes place for the image correction. Thirdly, analysis techniques are used to outline the areas with significant alterations, which is what strictly concerns change detection. Finally, the analysis and validation should be performed with the use of the ancillary data, which can be field or official statistical data, and using techniques to estimate the precision of the whole process. (Singh et al., 1989; Lu et al., 2004; Chuvieco, 1998; Coppin et al., 2004).

In this study, two Landsat ETM+ images acquired in 2000 and 2003 were used. In order to minimize the effects from atmospheric effects and seasonal differences (phenotype differences), images from the same time of the year, or as close as possible, were obtained. In the Figure 5 is shown the methodological approach. Two approaches were compared in order to assess differences between both methodologies. The steps followed were: 1) the acquisition and pre-processing; 2) changes analyses made through MAD and Postclassification, 3) MAD classification in order to compare with Post-classification technique; 4) A change matrix acquisition was undertaken followed by; 5) Result analysis and qualitative comparison. 


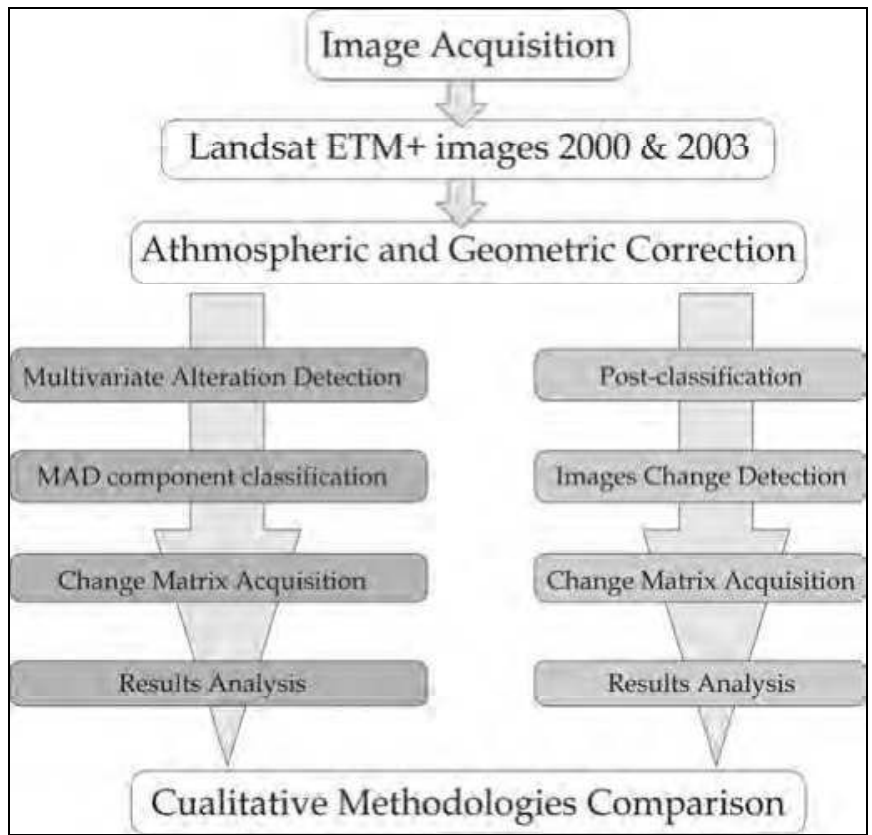

Fig. 5. Methodological approach. The figure shows the methodology followed for MAD in the left and Post classification in the right.

\subsubsection{Results of the comparative study}

We selected a set of three areas where notorious land cover change had occurred. The change map was extracted from the 6 components of the MAD transformation and the Chi square probability image, using a maximum likelihood algorithm and a threshold method. The change classes were the following:

1. TDF to bare soil and agriculture crop

Other vegetation to bare soil and agriculture crop

2. Agriculture crop to other vegetation

First of all, the Landsat imagery shows greater greenness in the year 2000 than in the year 2003. However, this trend, which holds for the bulk of TDF, may be explained by a difference in forest phenology stages between March 2000 and February 2003, because of greater precipitations earlier in year 2000 than in year 2003. Indeed, the rivers and water bodies are wider in 2000 than in 2003.

Most changes due to deforestation seemed to have occurred in easily accessible sites, within few pixels of human settlements, water bodies and agricultural areas in 2000. This indicated deforestation processes associated with an expansion of agricultural activity.

Three image subsets are shown in figures 6, 7 and 8, where a visual inspection helped the interpretation of the change detection. Red, orange and green colors referred respectively to deforestation of the TDF, removal of other vegetation types to a land use, and conversion of agriculture crop to a type of vegetation cover.

A visual inspection reveals that the post-classification approach yielded a much larger change surface than the MAD approach. 


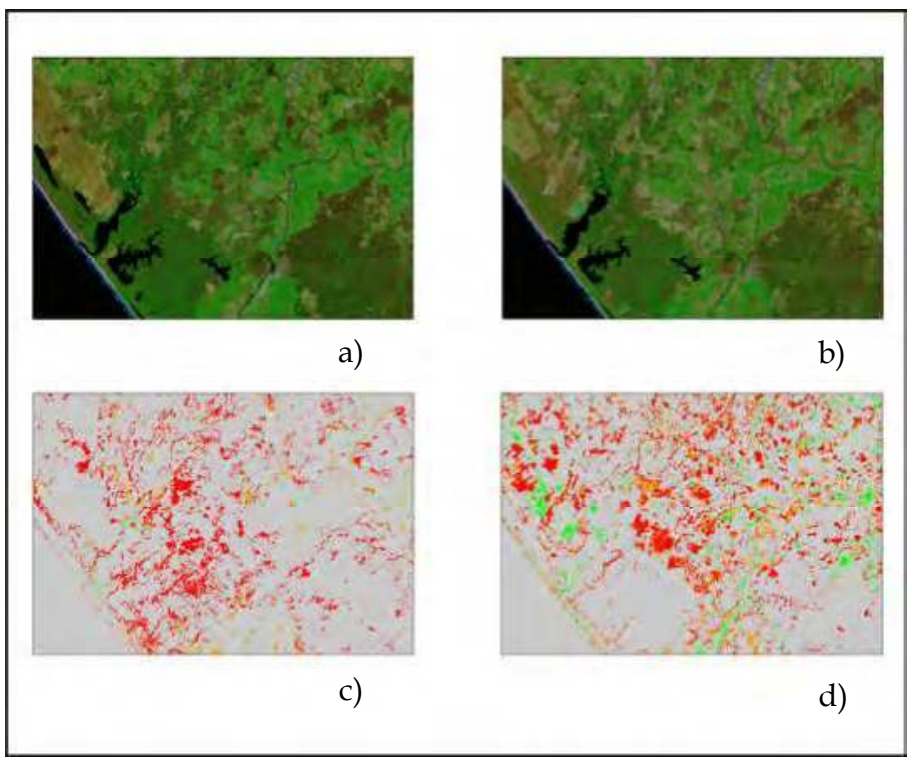

Fig. 6. Inset 1: a) Original Landsat ETM+ 2000; b) Original Landsat ETM+ 2003; c) Postclassification change map; d) Multivariate Alteration Detection change map.

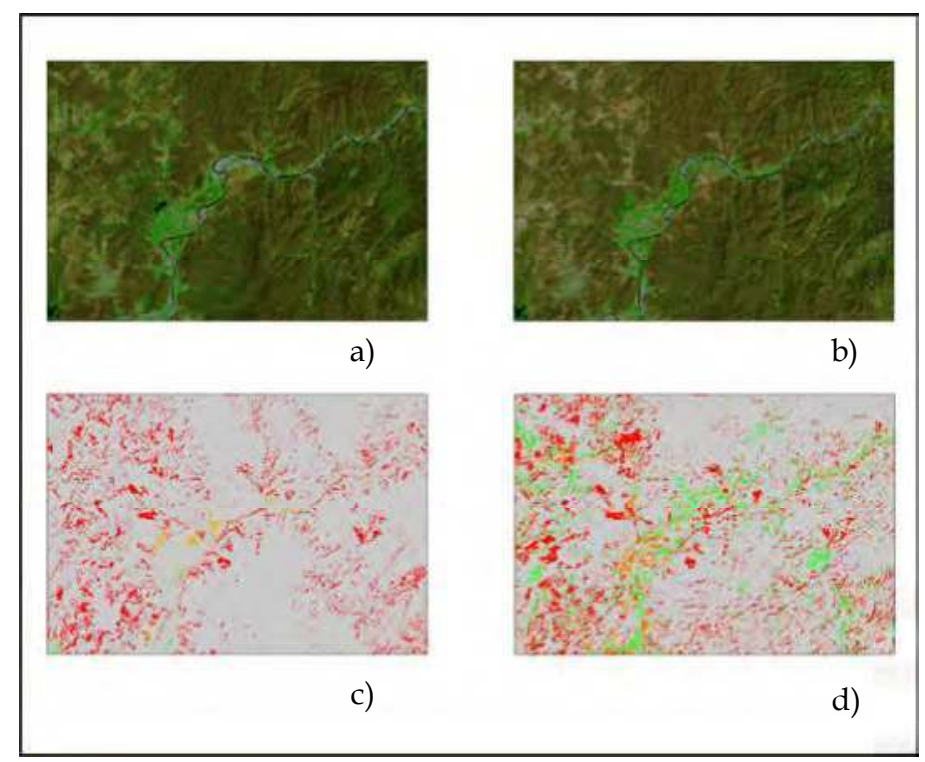

Fig. 7. Inset 2: a) Original Landsat ETM+ 2000; b) Original Landsat ETM+ 2003; c) Postclassification change map; d) Multivariate Alteration Detection change map. 
A close qualitative analysis of the MAD change map indicated a relatively good match between large red patches with actual occurrences of removal of TDF. By contrast, there seem to be a few inconsistencies for classes indicated in orange and green. Much green occurrence corresponded to a change of soil moisture or vegetative state of a crop field (agricultural crop in 2000 and 2003). The spectral signatures of some of these crop fields are indeed close to that of a TDF, which makes it difficult to detect by any of the methods. In figure 8 , many patches detected as deforestation by the post-classification method are in fact changes in crop conditions.

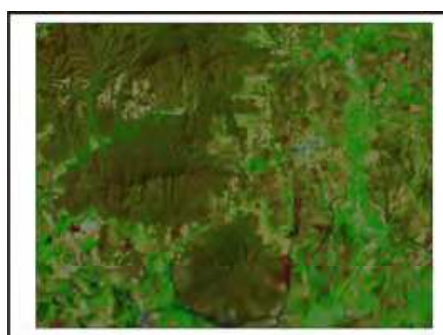

a)

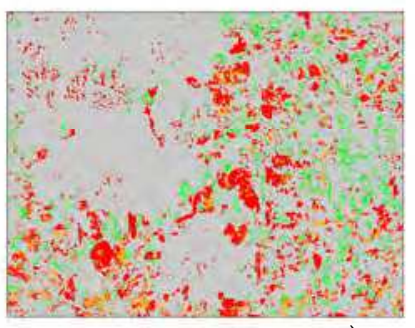

c)

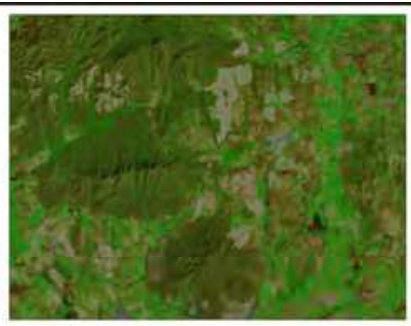

b)

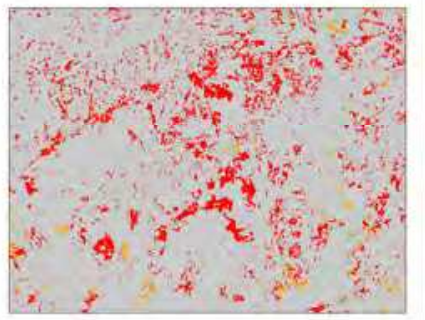

d)

Fig. 8. Inset 3: a) Original Landsat ETM+ 2000; b) Original Landsat ETM+ 2003; c) Postclassification change map; d) Multivariate Alteration Detection change map.

In the mountainous area, where TDF prevails (see figures 7), red spots would indicate many small change patches according to the post-classification method, and less so according to the MAD approach. These red spot most likely correspond to false changes due to misregistration errors of pixels located in steep terrain or near to a river bank. Overall, it is likely that the post-classification method largely overestimates total land cover change.

The directionality of changes is observed on the change matrices (Tables 2 and 3). From the first method (MAD), the results showed a total area of $247.2 \mathrm{~km}^{2}$ of deforestation, whereas the post-classification method resulted in a higher change with $294.7 \mathrm{~km}^{2}$. Regarding to the areas with the opposite process ("forestation"), the matrix showed an area of $89 \mathrm{~km}^{2}$ and $29 \mathrm{~km}^{2}$ for MAD and for post-classification, respectively. 


\begin{tabular}{|l|c|c|c|c|c|}
\hline \multicolumn{1}{|c|}{ MAD } & $\begin{array}{c}\text { Other } \\
\text { vegetation }\end{array}$ & Agriculture & $\begin{array}{c}\text { Bare } \\
\text { land }\end{array}$ & $\begin{array}{c}\text { Deforested } \\
\text { area }\left[\mathbf{k m}^{2}\right]\end{array}$ & $\begin{array}{c}\text { Regenerated } \\
\text { area }\left[\mathbf{k m}^{2}\right]\end{array}$ \\
\hline Tropical Dry Forest & NA & 144145 & 55641 & 179.8074 & \\
\hline Other vegetation & NA & 41773 & 33218 & 67.4919 & \\
\hline Agriculture & 99021 & NA & NA & & 89.1189 \\
\hline & & & Total & $\mathbf{2 4 7 . 2 9 9 3}$ & $\mathbf{8 9 . 1 1 8 9}$ \\
\hline
\end{tabular}

Table 2. Change matrix resulted from MAD technique.

\begin{tabular}{|l|c|c|c|c|c|}
\hline \multicolumn{1}{|c|}{ Post-classification } & $\begin{array}{c}\text { Other } \\
\text { vegetation }\end{array}$ & Agriculture & $\begin{array}{c}\text { Bare } \\
\text { land }\end{array}$ & $\begin{array}{c}\text { Deforested } \\
\text { area [km2] }\end{array}$ & $\begin{array}{c}\text { Regenerated } \\
\text { area [km2] }\end{array}$ \\
\hline Tropical Dry Forest & NA & 274459 & 3211 & 249.903 & \\
\hline Other vegetation & NA & 49551 & 316 & 44.8803 & \\
\hline Agriculture & 32698 & NA & NA & & 29.4282 \\
\hline & & & Total & 294.7833 & 29.4282 \\
\hline
\end{tabular}

Table 3. Change matrix resulted from Post-Classification technique.

\section{Conclusion}

Society faces the challenge of developing strategies to reduce the negative environmental impacts of land use change across multiple services and scales while maintaining social and economic benefits. This is why it is important to measure changes and find optimal techniques to measure them. Remote sensing is a valuable tool for monitoring land use and land cover. In the case of Tropical Dry Forests, the change in land cover is challenging because of its unsteady reflectance characteristics. Within a context of climatic change, the TDF is an important ecosystem for its preservation due to the ecosystem services it presents as well as for its high value in carbon capturing. It is necessary to diminish the land use and land cover changes in the TDF because of its high value in content of carbon. One of the necessary tasks to diminish climatic change is the creation of studies that focus on specific ecosystems where the changes in land use dynamics are made at a local and regional level.

This research contributes by exploring change detection techniques in the challenging settings of tropical sub-humid conditions, towards an optimization of tropical land use change detection. The Multivariate Alteration Detection technique was tested against a more conventional technique (Post-classification), on a pilot area where TDF prevails in Mexico.

In the case of post-classification detection, the high amount of detected change could be interpreted as a large overestimation of change. In both approaches, classes of potential change included false change, such as pixels affected by small misregistration errors in heterogeneous landscapes and next to steep terrain, and signal change within a particular class (change of soil moisture conditions within the agriculture class for example). A possible interpretation was that many categories of false changes were difficult to handle with post-classification whereas they could be handled better with the MAD technique. 
Indeed, post-classification is a three step process (classification of the first image, classification of the second image, and then comparison of two layers) where the interpreter has to 'foresee' potential detection problems at each step. By contrast, each component of the MAD data represented a potential change type. This change type could have been a kind of false change, or a change within a particular class. In each case, the interpreter could directly handle the potential problem of the change type in a supervised manner. Instead of this, in post-classification, the change within a particular class would have to be detected ('foreseen') at the classification step.

In the case of TDF landscapes, where the phenology causes forests to be confounded with grassland or cropland, the characterization of each class is in itself a difficult task, which needs a certain amount of supervision. In such case, it is worth concentrating the efforts of the interpreter directly on change classes rather than first on thematic classes and then on change classes.

The global environmental challenge includes maintaining land use surfaces below a reasonable level, intending to reach a trade-off between immediate human needs and the capacity of ecosystems to provide goods and services in the future. Studies in deforestation and land use/land cover change made at a regional and local level have more and more importance every day creating models that help understand the climatic variations.

\section{References}

Bullock, S. Mooney, H. \& Medina, E. (1995). Seasonally dry tropical forests. Cambridge: Cambridge University Press. 450 pp.

Bruzzone, L., Fernandez Prieto, D. (2000). A minimum-cost thresholding technique for unsupervised change detection, International Journal of Remote Sensing, Vol. 21, No. 18, 2000, pp. 3539 - 3544 . DOI: 10.1080/014311600750037552

Burgos A. \& Maass M.J. (2004). Vegetation change associated with land-use in tropical dry forest areas of Western Mexico, Agriculture, Ecosystems and Environment,104 pp. $475-481$.

Canty M.J., Nielsen A.A. and Schmidt, M. (2004). Automatic radiometric normalization of multitemporal satellite imagery. Remote Sensing of Environment Vol. 91(3-4), pp.441451.

Canty M.J and Nielsen A.A.(2006). Visualization and unsupervised classification of changes in multispectral satellite imagery. International Journal of Remote Sensing Vol.27, No.(18), pp.3961-3975.

Canty M.J. and Nielsen A.A. (2008). Automatic Radiometric Normalization of Multitemporal Satellite Imagery with the Iteratively Re-weighted MAD Transformation. Remote Sensing of Environment Vol. 112, No (3), pp.1025-1036.

Canty, M. J., (2010), Image Analysis, Classification and Change Detection in Remote Sensing: With algorithms for ENVI/IDL, 2nd edition, pp. 249-253., ISBN: 978-14200-8713-0

Castillo, A., Dominguez, García, A., Quesada, M. \& Vega, J, (2007). Proyectos de desarrollo turísticos "La Huerta"(clave:14JA2006T0018) y "TAMBORA " (Clave:14JA20- 
06T0011) en áreas vecinas a la reserva de la biosfera Chamela-Cuixmala. Panel técnico de análisis. Universidad Nacional Autónoma de México.

Ceballos, G \& García, A. (1995). Conserving Neotropical Biodiversity: The Role of Dry Forests in Western Mexico. Conservation Biology, Vol. 9, No (6), pp. 1349-1353.

Chuvieco, E. (1998). El factor temporal en teledetección: evolución fenomenológica y análisis de cambios. Revista de Teledetección, No.10, pp. 1-9.

Chuvieco, E. (2002). Teledetección ambiental: la observación de la Tierra desde el espacio. Ariel. España. pp. 439-441. ISBN: 8434480476

Comisión Intersecretarial de Cambio Climático, México (2009). Cuarta Comunicación Nacional ante la Convención Marco de las Naciones Unidas sobre el Cambio Climático. Secretaría de Medio Ambiente y Recursos Naturales \& Instituto Nacional de Ecología, México.

Constanza, R., d'Arge, R., de Groot, R., Farber, S., Grasso, M., Hannon, B., Limburg, K., Naeem, S., O’Neill, R., Paruelo, J., Raskin, R., Sutton, P. \& Van den Belt, M. (1987). The value of the world's ecosystem services and natural capital. Nature, Vol. 387, No. 15, pp. 253-260.

Coppin, P. R. \& Bauer, M. E. (1996). Change detection in Forest Ecosystems with Remote Sensing Digital Imagery. Remote Sensing Reviews, No. 13, pp. 207-234.

Couturier, S. (2010). A fuzzy-based method for the regional validation of global maps: the case of MODIS-derives phonological classes in a mega-diverse zone, International Journal of Remote Sensing, Vol.31, No. 22, pp. 5797-5811.

Estrada-Salvador \& Navar, (2009). Flujos de carbono por deforestación en la selva baja caducifolia del estado de Morelos, México. XIII Congreso Forestal Mundial, Buenos Aires, Argentina.

Feeley, K.J., Gillespie, T.W., Terborgh, J.W. (2005). The Utility of Spectral Indices from Landsat ETM+ for Measuring the Structure and Composition of Tropical Dry Forests1, Biotropica Vol. 37, No. 4, pp. 508-519, ISSN 1744-7429.

Flores V, O. \& Gerez, P. (1994). Biodiversidad y conservación en México: vertebrados, vegetación y uso de suelo. CONABIO y UNAM. México.

Goetz, S., Baccini, A., Laporte, N., Johns, T., Walker, W., Kellndorfer, J., Houghton, R., and Sun, M. (2009) Mapping and monitoring carbon stocks with satellite observations: a comparison review, Carbon Balance and Management, 4:2.

Griscom, H. P. Ashton, M.S., (2010), Restoration of dry forest in Central America: A review of pattern and process, Forest Ecology and Management, Vol. 261, No. 10, pp.15641574, ISSN 0378-1127.

Houet T. and Verburg P.H. (2010), Monitoring and modelling landscape dynamics, Landscape Ecol. 25.pp.163-167, DOI 10.1007/s10980-009-9417-x

Intergovermental Panel on Climate Change (IPCC). (1995). Climate Change. The Suplementary Report to the IPCC Scientific Assessment. Cambridge University Press. Cambridge, Inglaterra.

Intergovermental Panel on Climate Change (IPCC), (1997). Estabilización de los gases atmosféricos de efecto invernadero: implicaciones físicas, biológicas y socioeconómicas. Documento técnico III. 
Intergovermental Panel on Climate Change (IPCC). (2002). Climate change and biodiversity. IPPCC technical paper V. WMO y UNEP.

Janzen, D.H., (1988). Tropical dry forests: the most endangered major tropical ecosystem. In: Wilson, E.O. (Ed.), Biodiversity, National Academy Press, Washington, pp. 130-137.

Jaramillo J. V., Boone Kauffman J., Rentería-Rodríguez L.,Cummings L. D. and Ellingson L. J . (2003). Biomass, Carbon, and Nitrogen Pools in Mexican Tropical Dry Forest Landscapes, Ecosystems 6. pp.609-629, DOI: 10.1007/s10021-002-0195-4

Jensen, J. (1996). Introductory Digital Image Processing A Remote Sensing Perspective. Prentice Hall, New Jersey.

Kalacska, M.. Sanchez-Azofeifa, G.A., Rivard, B., Caelli, T., White, P. \& Calvo-Alvarado, M. (2007). Ecological fingerprinting of ecosystem succession: Estimating secondary tropical dry forest structure and diversity using imaging spectroscopy. Remote Sensing of Environment, Vol. 108, No 1, pp. 82-96.

Kalacska, M., Sanchez-Azofeifa, G.A., Rivard, B., Calvo-Alvarado, M. \& Quesada, M. (2008). Baseline assessment for environmental services payments from satellite imagery: a case study from Costa Rica and Mexico. Journal of environmental management, Vol. 88, No. 2, pp. 348-59.

Lambin, E.F. (1997). Modelling and monitoring land-cover change processes in tropical regions. Progress in Physical Geography. No. 21, pp. 375-393.

López Granados, E.M., G. Bocco \& M.E. Mendoza. (2001). Cambio de cobertura vegetal y uso de suelo. En: Mendoza, M.E., G. Bocco y E. López 2001. Regionalización ecológica, conservación de recursos naturales y ordenamiento territorial en la cuenca del lago de Cuitzeo, Michoacán. Informe Técnico. Proyecto No. 98306024. Programa SIMORELOS - CONACYT, México 273 pp

Lu, D., Mausel, P., Brondízio, E. \& Moran, E. (2004). Change detection techniques. International Journal of Remote Sensing. Vol. 25, No. 12, pp. 2365-2401

Lucas, R.M., Held, A.A., Phinn, S.R. and Saatchi, S., (2004), Tropical forests. In Remote Sensing for Natural Resource Management and Environmental Monitoring, S.L. Ustin (Ed.), pp. 239-315 (Hoboken, NJ: John Wiley).

Maass, J.M., Balvanera, P., Castillo, A., Daily, G.C., Mooney, H.A., Ehrlich, P., Quesada, M., Miranda, A., Jaramillo, V.J., García-Oliva, F., Martínez-Yrizar, A., Cotler, H., LópezBlanco, J., Pérez-Jiménez, A., Búrquez, A., Tinoco, C., Ceballos, G., Barraza, L., Ayala, R.\& Sarukhán, J. (2005). Ecosystem Services of Tropical Dry Forests : Insights from Long- term Ecological and Social Research on the Pacific Coast of Mexico. Ecology And Society, Vol. 10, No. 1, pp. 17.

Maas, J.M. (1995). Conversion of tropical dry forest to pasture and agriculture. In: Seasonally dry tropical forests, Bullock, S. H., Mooney, H.A. \& Medina, E. pp. 326-345. Cambridge University Press, ISBN 0521435145, Great Britain.

Martínez-Yrízar, A. (1995). Biomass distribution and primary productivity of tropical dry forests. En: Bullock, S. H., Mooney, H. \& Medina, E. (eds), Seasonally dry tropical forests. Cambridge University Press. pp. 326-345. 
Martínez-Yrízar, A., Maass, M., Pérez-Jiménez, L. A. \& Sarukhán, J. (1996). Net primary productivity of a tropical deciduous forest ecosystem in western Mexico. Journal of Tropical Ecology. Vol. 12, No. 1, pp. 169-175.

Menaut, J.C., Lepage, M. \& Abbadie, L. (1995). Savannas, woodlands and dry forest in Africa. In: Seasonally dry tropical forests, Bullock, S. H., Mooney, H.A. \& Medina, E. pp. 64-88. Cambridge University Press. ISBN 0521435145, Great Britain.

Miles, L., Newton, A.C., DeFries, R. S., Ravilious, C., May, I., Blyth, S., Kapos, V. \& Gordon, J. (2006). A global overview of the conservation status of tropical dry forests. Journal of Biogeography, Vol. 33, No. 3, pp. 491-505.

Murphy, P.G. \& Lugo, A.E.,(1986). Ecology of tropical dry forest. Annual Review of Ecology and Systematics 17: 67-88.

Murphy, P.G. (1995). Dry forest of Central America and the Caribbean. In: Seasonally dry tropical forests, Bullock, S. H., Mooney, H.A. \& Medina, E. pp. 9-29. Cambridge University Press. ISBN 0521435145, Great Britain.

Nielsen, A.A. and Conradsen, K. (1997). Multivariate Alteration Detection (MAD) in Multispectral, Bi-temporal Image Data: A New Approach to Change Detection Studies. IMM Technical Report No. 1997-11.

Nielsen, A.A., Conradsen, K. and Simpson, J.J. (1998). Multivariate Alteration Detection (MAD) and MAF Post-Processing in Multispectral, Bi-temporal Image Data: New Approaches to Change Detection Studies. Remote Sensing of Environment Vol. 64, No.1, pp. 1-19.

Niemeyer, I., Marpu, P.R. \& Nussbaum, S. (2008). Change detection using object features. In: object-based image analysis. Spatial concepts for knowledge-driven Remote sensing applications. Thomas Blaschke, Stefan Lang and Geoffrey J. Hay (eds).

Nori, W., Elsidding, E. and Niemeyer, I., (2008), “Detection of Land Cover Changes Using Multi-Temporal Satellite Imagery", The International Archives of the Photogrammetry, Remote Sensing and Spatial Information Sciences. Vol.37, No. 7, pp. 947-951.

Ordoñez, B. (1999). Captura de carbon en un bosque templado: el caso de San Juan Nuevo, Michoacán. INE-SEMARNAT, México.

Ordóñez, B. \& Masera, O. (2001). Captura de carbono ante el cambio climático. Madera y bosques. Vol. 7, No.1, pp. 3-12. Instituto de Ecología, Xalapa.

Ortiz, R. V. 2005. Hyperspectral Change Detection Using Temporal Principal Component Analysis. Master thesis. Universidad de Puerto Rico. Mayaguez Campus

Pacifici, F., Del Frate, F., Solimini, C. \& Emery, W. J. (2007). An Innovative Neural-Net Method to Detect Temporal Changes in High-Resolution Optical Satellite imagery, IEEE Transactions on Geoscience and Remote Sensing, Vol. 45, No. 9, pp. 2940-2952.

Pielke, R. A. Sr, Gregg Marland, Richard A. Betts, Chase, T., Eastman, J., Niles, J., Niyogi, D. \& Running, S. (2002). The Influence of Land-use Change and Landscape Dynamics on the Climate System: Relevance to Climate-change Policy Beyond the Radiative Effect of Greenhouse Gases. Philosophical Transactions of the Royal Society A, No. 360, pp. 1705-1719. 
Pfaff, A., Kerr, S., Flint Hughes, R., Liu, S., Sánchez-Azofeifa, A., Schimel, D., Tosi, J. \& Watson, V. (2000). The Kyoto protocol and payments for tropical forest: An interdisciplinary method for estimating carbon-offset supply and increasing the feasibility of a carbon market under the CDM. Ecological Economics, Vol. 35, No. 2, pp. 203-221

Quadri de la Torre, G. (2000). Incendios forestales y deforestación en México: una perspectiva analítica. Comisión de estudios del sector privado para el desarrollo sustentable (CESPEDES), México.

Ramírez Bojórquez P.R. (2006). Análisis espacial de la cobertura de manglar en los municipios de Tecuala y Santiago Ixcuintla, Nayarit en el periodo de 1973-2005. Tesis de Maestría. CIAD, A.C. México.

Reyes C., Taylor F., Martínez E. y López F. (2006). Geo-Cybernetics: A new Avenue of Research in Geomatics, Cartographica, 41, Issue 1.DOI. 10.3138/C034-6P5T-W322$1 G 72$

Rosete, A., Pérez, J.L. \& Bocco, F. (2008). Cambio de uso de suelo y vegetación en la Península de Baja California, México. Investifaciones Geográficas, Boletín del Instituto de Geografía, UNAM. No. 67, pp 39-58.

Rundel, P.W., Boonpragob, K. (1995). Dry forest of Thailand. In: Seasonally dry tropical forests, Bullock, S. H., Mooney, H.A. \& Medina, E. pp. 93-119. Cambridge University Press. ISBN 0521435145, Great Britain.

Rzedowsky, J. (1978). Vegetación de México. Ed. Limusa. Mexico

Sánchez-Azofeifa A.G., (2009). Land cover and conservation in the area of influence of the Chamela-Cuixmala Biosphere Reserve, Mexico. Forest Ecology and Management Vol. 258, pp.907-912.

Sampaio, E.V.S.B. (1995). Overview of the Brazilian caatinga. In: Seasonally dry tropical forests, Bullock, S. H., Mooney, H.A. \& Medina, E. pp. 35-58. Cambridge University Press. ISBN 0521435145, Great Britain.

Serra, P., Pons, X. \& Saurí, D. (2001). Protocolo para la detección de cambios a través de diferentes sensores. Revista de teledetección. No. 16, pp 17-24.

Sui, H., Zhou, Q., Gong, J. \& Ma, G. (2008). Processing of multitemporal data and change detection. In: Advances in Photogrammetry, Remote Sensing and Spatial Information Science: 2008 ISPRS Congress Book. Li, Z., Chen, J. \& Baltsavias (Eds).

Thompson, B. (1984). Canonical Correlation Analysis. Uses and Interpretation. Series: Quantitative Applications in the Social Sciences. Sage University. USA. pp.8-25. USA.ISBN 0-8039-2392-9. OK

Trejo, I. \& Dirzo, R. (2000). Deforestation of seasonally dry tropical forest a national and local analysis in Mexico. Biological Conservation, Vol. 94, No. 2, pp.133-142.

U.S. Geological Survey (USGS), (2010), In: http://landsat.usgs.gov/ about_project_ descriptions.php.

William R. E. (1985), Climatic change and the broad scale distribution of terrestrial ecosystem complexes, Climatic Change, No, 7 pp. 29-43. 
Wyatt, B.K., 2000. Remote sensing of land cover and land cover change. In: Observing Land from Space: Science, Customers and Tecnology. Verstraete et al. (Eds) pp. 127-133.

Zhang, L., Liao, M., Yang, L., \& Lin. H. (2007). Remote Sensing Change Detection Based in Canonical Correlation Analysis and Contextual Bayes Decision. American Society for Photogrammetry and Remote Sensing Vol.73, No, 3. pp. 311-318. 


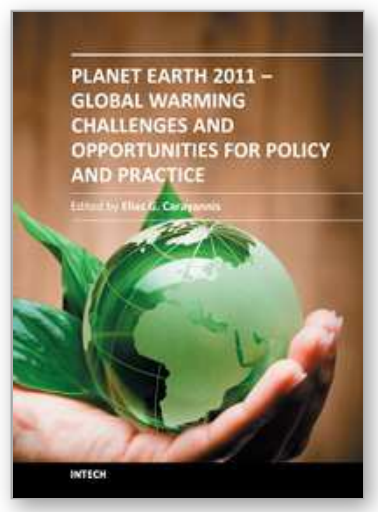

\section{Planet Earth 2011 - Global Warming Challenges and Opportunities for Policy and Practice}

Edited by Prof. Elias Carayannis

ISBN 978-953-307-733-8

Hard cover, 646 pages

Publisher InTech

Published online 30, September, 2011

Published in print edition September, 2011

The failure of the UN climate change summit in Copenhagen in December 2009 to effectively reach a global agreement on emission reduction targets, led many within the developing world to view this as a reversal of the Kyoto Protocol and an attempt by the developed nations to shirk out of their responsibility for climate change. The issue of global warming has been at the top of the political agenda for a number of years and has become even more pressing with the rapid industrialization taking place in China and India. This book looks at the effects of climate change throughout different regions of the world and discusses to what extent cleantech and environmental initiatives such as the destruction of fluorinated greenhouse gases, biofuels, and the role of plant breeding and biotechnology. The book concludes with an insight into the socio-religious impact that global warming has, citing Christianity and Islam.

\section{How to reference}

In order to correctly reference this scholarly work, feel free to copy and paste the following:

Betsabé de la Barreda-Bautista, Alejandra A. López-Caloca, Stephane Couturier and José Luis SilvánCárdenas (2011). Tropical Dry Forests in the Global Picture: The Challenge of Remote Sensing-Based Change Detection in Tropical Dry Environments, Planet Earth 2011 - Global Warming Challenges and Opportunities for Policy and Practice, Prof. Elias Carayannis (Ed.), ISBN: 978-953-307-733-8, InTech, Available from: http://www.intechopen.com/books/planet-earth-2011-global-warming-challenges-andopportunities-for-policy-and-practice/tropical-dry-forests-in-the-global-picture-the-challenge-of-remotesensing-based-change-detection-in

\section{INTECH}

open science | open minds

\section{InTech Europe}

University Campus STeP Ri

Slavka Krautzeka 83/A

51000 Rijeka, Croatia

Phone: +385 (51) 770447

Fax: +385 (51) 686166

www.intechopen.com

\section{InTech China}

Unit 405, Office Block, Hotel Equatorial Shanghai

No.65, Yan An Road (West), Shanghai, 200040, China 中国上海市延安西路65号上海国际贵都大饭店办公楼 405 单元

Phone: +86-21-62489820

Fax: +86-21-62489821 
(C) 2011 The Author(s). Licensee IntechOpen. This chapter is distributed under the terms of the Creative Commons Attribution-NonCommercialShareAlike-3.0 License, which permits use, distribution and reproduction for non-commercial purposes, provided the original is properly cited and derivative works building on this content are distributed under the same license. 